\title{
A comparative study of efficacy of oral pregabalin and clonidine for attenuation of pressor response to intubation
}

\author{
Haramritpal Kaur ${ }^{1 *}$, Jatin Gupta ${ }^{1}$, Amandeep Singh ${ }^{2}$, Gurpreet Singh ${ }^{1}$, \\ Anshul Dahuja ${ }^{3}$, Parveen Rajora ${ }^{4}$, Rubina Rana ${ }^{1}$, Naresh Baghla ${ }^{1}$
}

\begin{abstract}
${ }^{1}$ Department of Anaesthesia, ${ }^{2}$ Department of Surgery, ${ }^{3}$ Department of Orthopaedics, ${ }^{4}$ Department of Obstetrics and Gynaecology, GGS Medical College and Hospital, Faridkot, Punjab, India
\end{abstract}

Received: 18 July 2021

Revised: 10 August 2021

Accepted: 11 August 2021

\section{*Correspondence:}

Dr. Haramritpal Kaur,

Email: amritk_dr@ggsmch.org

Copyright: (C) the author(s), publisher and licensee Medip Academy. This is an open-access article distributed under the terms of the Creative Commons Attribution Non-Commercial License, which permits unrestricted non-commercial use, distribution, and reproduction in any medium, provided the original work is properly cited.

\begin{abstract}
Background: Endotracheal intubation is associated with hemodynamic stress responses. Various drugs have been used in the past to attenuate the pressor response; however, none has been proved to be ideal. Present study was planned to evaluate the oral pregabalin $150 \mathrm{mg}$ and clonidine $200 \mu \mathrm{g}$ for attenuation of pressor response to intubation. Methods: The study was conducted on 100 adult patients of either gender scheduled to undergo elective surgeries under general anaesthesia (GA). The patients were randomly allocated into 2 groups. In group A patients received pregabalin $150 \mathrm{mg}$ and in group B patients received clonidine $200 \mu \mathrm{g}$ orally. The hemodynamic parameters were recorded until 10 minutes after intubation. The sedation, anxiety and side effects were also assessed.

Results: In clonidine group, the mean HR remained below the baseline value at all the time intervals. In pregabalin group, the mean HR remained below the baseline value at most of the time intervals but increased above baseline just after intubation (T0i) and 1 minute after intubation (T1i) where increase was only $1.488 \pm 1.20 \%$ and $0.45 \pm 1.16 \%$ respectively from baseline. In both pregabalin and clonidine groups, the mean SBP and MAP remained below the baseline value $(\mathrm{Tb})$ at all the time intervals from T0.5 to T10i. Both clonidine and pregabalin provided adequate anxiolysis and sedation with pregabalin providing more pronounced sedation and anxiolysis than clonidine.

Conclusions: Both clonidine and pregabalin are effective oral premedication drugs for attenuation of the pressor response to laryngoscopy and endotracheal intubation.
\end{abstract}

Keywords: Clonidine, Pregabalin, Pressor response, Laryngoscopy, Intubation

\section{INTRODUCTION}

Laryngoscopy is an important procedure in day to day practice of anaesthesiology. It is used to secure airway not only during surgeries, but also in critically ill patients in intensive care unit. So, it is necessary for every anaesthesiologist to gain proficiency in securing the airway and administering patient care in the safest possible manner. Laryngoscopy and tracheal intubation produce sympathetic over drive by catecholamine release resulting in hypertension and tachycardia. ${ }^{1}$ This is usually well tolerated by healthy individuals but susceptible patients like of ischemic heart disease, old age, diabetes may succumb to the hemodynamic fluctuations. ${ }^{2}$ Irritation of the airway stimulates the proprioceptors around the glottis and the trachea.

The afferent impulse travels via glossopharyngeal and vagus nerve to the brain stem producing autonomic nervous system stimulation, causing tachycardia and hypertension. ${ }^{3}$ In a study it was observed that average rise of systolic blood pressure, diastolic blood pressure and heart rate in response to endotracheal intubation in normotensive patients was by $53 \mathrm{mmHg}, 34 \mathrm{mmHg}$ and 
23 beats/min respectively. ${ }^{1}$ The outcome of these hemodynamic changes was increased load on the heart and increased oxygen demand by myocardium. Various strategies used to prevent this stress responseincluding deepening the level of anaesthesia, intravenous local anaesthetic agents like lignocaine, topical anaesthesia of upper respiratory tract, beta adrenergic blocking agents, vasodilators like sodium nitroprusside, calcium channel blockers like verapami, narcotic analgesics like fentanyl, sufentanil and alfentanil. ${ }^{1,4-11}$ Since none of these drugs proves to be the best choice for attenuating the pressor response, the quest continues. Recently, an increasing emphasis has been made on the use of non-opioid drugs as a part of multimodal regimen for decreasing anxiety as well as the intubation response. The ideal agent should be effective and pleasant to be taken orally, should produce sedation and ease of separation, should facilitate smooth induction of anaesthesia, should not impair cardiovascular stability. Some recent studies have shown that drugs such as clonidine and pregabalin can decrease stress response due to laryngoscopy and intubation.

Pregabalin, a gabapentinoid compound, is a drug with analgesic, anticonvulsant and anti anxiety effects mainly used for the management of neuropathic pain, neuralgia occurring post herpes infection and as adjuvant for the treatment of partial onset seizures. Recently it has also been used in different dosages with varying success to blunt the haemodynamic response to intubation. ${ }^{12}$

Clonidine is an alpha- 2 adrenergic agonist which has been used for many years as an antihypertensive and as negative chronotropic agent. ${ }^{13}$ During general anaesthesia clonidine enhances intraoperative circulatory stability by reducing catecholamine levels. ${ }^{14}$ It has many properties of an ideal premedicant and also has beneficial effects on haemodynamics during stressful conditions like laryngoscopy and endotracheal intubation. Only few studies are available comparing the efficacy of pregabalin and clonidine in controlling haemodynamic stress response throughout the peri-intubation period. In view of this observation the present study is planned to evaluate and compare the efficacy of orally administered pregabalin $150 \mathrm{mg}$ and clonidine $200 \mu \mathrm{g}$ for attenuation of pressor response to intubation in patients undergoing elective surgeries under general anaesthesia.

\section{METHODS}

The present study was conducted as prospective randomized controlled manner in GGS Medical college and Hospital, Faridkot, Punjab (India) from April 2019 to March 2020.

\section{Inclusion criteria}

Inclusion criteria were; American society of anaesthesiologists (ASA) physical status I \& II, 20-60 years of either gender.

\section{Exclusion criteria}

Patient with anticipated difficult airway, morbid obesity, known case of hypertension, history of allergy to any anaesthetic medication/study drugs, on sedatives, hypnotics or sympatholytics and pregnant patients were excluded from the study.

A written informed consent was obtained from all patients.

The sample size was calculated using mean arterial pressure as a variable achieving $95 \%$ power to detecta difference of proportion of 0.104 between two groups assuming the proportion of group one as 0.958 under null hypothesis and 1.062 under the alternate hypothesis. ${ }^{15}$ Using a two sided $\mathrm{z}$ test with pooled variance and significance level of 0.01 , the minimum required sample size in each group was 33 . The sample size of 50 patients in each group, comprising a total of 100 patients was included for the purpose of this study. A day before detailed pre-operative assessment was done. All patients were investigated. Minimum 6 hours of fasting was ensured pre-operatively. The various treatment groups were, group A $(\mathrm{N}=50)$ : patients received pregabalin $150 \mathrm{mg}$ orally and group $\mathrm{B}(\mathrm{N}=50)$ : patients received clonidine $200 \mu \mathrm{g}$ orally.

The drug from the closed envelope was drawn and given to the patient with sip of water 90 minutes before induction of anaesthesia. Patients were kept blinded about the study group allocation. The standard monitors were attached. Baseline heart rate, blood pressure (systolic, diastolic and mean arterial pressure), sedation and anxiety scores were recorded at the time of administration of study drugs and then sequentially at 30 minutes, 60 minutes and at 90 minutes (just before induction of anaesthesia) after administration of study drug. Following anxiety and sedation scores were used: anxiety score : ( 0 patient quiet and comfortable; 1-patient uneasy; 2-patient worried or anxious ; 3-patient very worried or very upset). ${ }^{13}$ Sedation score used was (1- wide awake; 2sleeping comfortably but responding to verbal commands; 3- deep sleep but arousable, 4- deep sleep but not arousable).

An intravenous access was obtained and crystalloid infusion of $6-8 \mathrm{ml} / \mathrm{kg}$ was started. All the patients were given fentanyl $(1 \mu \mathrm{g} / \mathrm{kg})$ before induction. After preoxygenation for three minutes with $100 \%$ oxygen, anaesthesia was induced with propofol $(1 \%)(2 \mathrm{mg} / \mathrm{kg})$. A direct laryngoscopy was done three minutes after the injection vecuronium $(0.1 \mathrm{mg} / \mathrm{kg})$ and the patients were intubated with appropriate size cuffed endotracheal tube by the senior anaesthesiologist present. Heart rate, blood pressure (systolic, diastolic, mean arterial pressure) were recorded after induction (just before intubation), just after intubation and then sequentially at first, second, third, fifth, eighth and tenth minute following intubation and were recorded as Ti, T0i ,T1i, T2i T3i, T5i ,T8i and 
T10i respectively. Anaesthesia was maintained with isoflurane and nitrous oxide to oxygen in ratio of $60 \%: 40 \%$. The patients were mechanically ventilated to maintain the normocapnia (end tidal $\mathrm{CO} 2$ between 35 and $40 \mathrm{mmHg}$ ). Surgery was not allowed to commence till the recordings are completed which shall be around ten minutes. The supplemental neuromuscular blockade was achieved with vecuronium maintenance dose. Patients were monitored for any side effects pertaining to drugs. After completion of surgery, residual neuromuscular block was antagonized with appropriate doses of neostigmine $(0.05 \mathrm{mg} / \mathrm{kg})$ and glycopyrrolate $(0.01$ $\mathrm{mg} / \mathrm{kg}$ ), and the extubation was performed using standard protocols. Data so collected, tabulated and coded in MS excel and was then analyzed using SPSS, computer software version 16. Continuous variables were presented as mean \& standard deviation (SD) while categorical variables were presented as percent. Continuous variables were analyzed using unpaired student $t$ test and Chi square test was used to find out association between two categorical variables, $\mathrm{p}<0.05$ was taken as significant and $<0.001$ as highly significant.

\section{RESULTS}

A total of 100 patients were enrolled in the study. The demographic variables that is age,gender, weight, height, body mass index (BMI) and ASA grade were similar in both the groups $(p>0.05)$ (Table 1). Duration of laryngoscopy and intubation in seconds and mallampatti grading (MPG) were also similar in both the groups (p>0.05) (Table 1).

Table 1: Study results of demographic variables.

\begin{tabular}{|llll|}
\hline Parameter & Group A & Group B & P value \\
\hline Age (years) & $35.94 \pm 8.876$ & $37.98 \pm 11.169$ & 0.315 \\
\hline Weight (Kg) & $64.24 \pm 7.317$ & $62.24 \pm 5.259$ & 0.120 \\
\hline Height (cm) & $162 . \pm 4.3$ & $160.86 \pm 4.998$ & 0.224 \\
\hline BMI (Kg/m2 ) & $24.462 \pm 2.498$ & $24.018 \pm 1.195$ & 0.260 \\
\hline Duration of laryngoscopy and intubation (Sec) & $11.94 \pm 1.5$ & $11.98 \pm 1.35$ & 0.941 \\
\hline Gender (male: female) & $24: 26$ & $23: 27$ & 0.841 \\
\hline Mallampatti grading (MPG) (grade I:II) & $29: 21$ & $27: 23$ & 0.687 \\
\hline ASA physical status (I:II) & $36: 14$ & $39: 11$ & 0.488 \\
\hline
\end{tabular}

NS $=$ Non significant $(\mathrm{p}$ value $>0.05$ )

Table 2: Comparison of mean change and percentage mean change in heart rate at various time intervals from baseline heart rate.

\begin{tabular}{|c|c|c|c|c|}
\hline $\begin{array}{l}\text { Change in HR } \\
\text { (Beats/min) }\end{array}$ & Study group & $\begin{array}{l}\text { Mean change from } \\
\text { baseline } \pm \text { SD }\end{array}$ & $\begin{array}{l}\text { \% change in mean from } \\
\text { baseline } \pm \text { SD }\end{array}$ & $P$ value \\
\hline \multirow{2}{*}{$\begin{array}{l}\text { Change in HR } \\
\text { (Tb) - (T0.5) }\end{array}$} & A & $1.50 \pm 0.51$ & $1.66 \pm 0.59$ & \multirow[t]{2}{*}{0.000} \\
\hline & $\mathrm{B}$ & $13.28 \pm 2.93$ & $14.36 \pm 3.10$ & \\
\hline \multirow{2}{*}{$\begin{array}{l}\text { Change in HR } \\
\text { (Tb) - (T1) }\end{array}$} & A & $1.20 \pm 067$ & $1.33 \pm 0.76$ & \multirow[t]{2}{*}{0.000} \\
\hline & B & $17.10 \pm 3.28$ & $18.48 \pm 3.50$ & \\
\hline \multirow{2}{*}{$\begin{array}{l}\text { Change in HR } \\
\text { (Tb) - (T1.5) }\end{array}$} & A & $0.64 \pm 0.63$ & $0.70 \pm 0.68$ & \multirow[t]{2}{*}{0.000} \\
\hline & B & $5.10 \pm 3.54$ & $5.48 \pm 3.74$ & \\
\hline \multirow{2}{*}{$\begin{array}{l}\text { Change in HR } \\
\text { (Tb) - (Ti) }\end{array}$} & A & $5.62 \pm 1.09$ & $6.19 \pm 1.24$ & \multirow[t]{2}{*}{0.000} \\
\hline & B & $13.84 \pm 6.72$ & $14.75 \pm 6.63$ & \\
\hline \multirow{2}{*}{$\begin{array}{l}\text { Change in HR } \\
\text { (Tb) - (T0i) }\end{array}$} & A & $-1.34 \pm 1.10$ & $-1.49 \pm 1.20$ & \multirow[t]{2}{*}{0.000} \\
\hline & B & $3.54 \pm 6.83$ & $3.5 \pm 7.16$ & \\
\hline \multirow{2}{*}{$\begin{array}{l}\text { Change in HR } \\
\text { (Tb) - (T1i) }\end{array}$} & A & $-1.82 \pm 1.26$ & $-2.02 \pm 1.39$ & \multirow[t]{2}{*}{0.000} \\
\hline & B & $2.7 \pm 6.94$ & $2.65 \pm 7.32$ & \\
\hline \multirow{2}{*}{$\begin{array}{l}\text { Change in HR } \\
\text { (Tb) - (T2i) }\end{array}$} & A & $0.01 \pm 1.17$ & $0.097 \pm 1.26$ & \multirow[t]{2}{*}{0.000} \\
\hline & B & $5.88 \pm 6.98$ & $6.09 \pm 7.23$ & \\
\hline \multirow{2}{*}{$\begin{array}{l}\text { Change in HR } \\
\text { (Tb) - (T3i) }\end{array}$} & A & $3.02 \pm 1.46$ & $3.33 \pm 1.62$ & \multirow[t]{2}{*}{0.000} \\
\hline & B & $10.68 \pm 6.90$ & $11.28 \pm 6.98$ & \\
\hline \multirow{2}{*}{$\begin{array}{l}\text { Change in HR } \\
\text { (Tb) - (T5i) }\end{array}$} & A & $4.52 \pm 1.90$ & $4.99 \pm 2.13$ & \multirow[t]{2}{*}{0.000} \\
\hline & B & $20.38 \pm 6.63$ & $21.80 \pm 6.38$ & \\
\hline \multirow{2}{*}{$\begin{array}{l}\text { Change in HR } \\
\text { (Tb) - (T8i) }\end{array}$} & A & $7.80 \pm 1.77$ & $8.61 \pm 2.09$ & \multirow[t]{2}{*}{0.000} \\
\hline & B & $21.38 \pm 6.63$ & $22.88 \pm 6.34$ & \\
\hline \multirow{2}{*}{$\begin{array}{l}\text { Change in HR } \\
\text { (Tb) - (T10i) }\end{array}$} & A & $11.48 \pm 1.89$ & $12.67 \pm 2.35$ & \multirow{2}{*}{0.000} \\
\hline & B & $21.66 \pm 6.70$ & $23.18 \pm 6.41$ & \\
\hline
\end{tabular}

$\mathrm{p}$ value $<0.001$ is highly significant 
Changes in mean HR are shown in (Table 2). In clonidine group, the mean HR remained below the baseline value (Tb) at all the time intervals from $\mathrm{T} 0.5$ to $\mathrm{T} 10 \mathrm{i}$, so no pressor response was observed in the form of increase in mean HR from the baseline value ( $\mathrm{Tb})$. In pregabalin group, the mean HR remained below the baseline value (Tb) at the time intervals of T0.5, T1, T1.5, Ti, T2i, T3i,
T5i, T8i and T10i but increased above baseline (Tb) just after intubation(T0i) and 1 minute after intubation (T1i) where increase was only $1.488 \pm 1.20 \%$ and $0.45 \pm 1.16 \%$ respectively from baseline (Table 2). Maximum rise in mean HR from the baseline was by $2.02 \%$ at 1 minute after intubation (T1i).

Table 3: Comparison of mean change and percentage mean change in mean arterial pressure (MAP) at various time intervals from baseline MAP between two groups.

\begin{tabular}{|c|c|c|c|c|}
\hline $\begin{array}{l}\text { Change in MAP } \\
(\mathrm{mmHg})\end{array}$ & $\begin{array}{l}\text { Study } \\
\text { Group }\end{array}$ & $\begin{array}{l}\text { Mean change from } \\
\text { baseline } \pm \text { SD }\end{array}$ & $\begin{array}{l}\text { \%change in mean from } \\
\text { baseline } \pm \text { SD }\end{array}$ & P value \\
\hline \multirow{2}{*}{$\begin{array}{l}\text { Change in MAP (Tb) - } \\
\text { (T0.5) }\end{array}$} & A & $4.16 \pm 0.71$ & $4.38 \pm 0.75$ & \multirow{2}{*}{0.000} \\
\hline & B & $7.68 \pm 3.26$ & $8.11 \pm 3.33$ & \\
\hline \multirow{2}{*}{ Change in MAP (Tb) - (T1) } & A & $7.06 \pm 0.84$ & $7.44 \pm 0.97$ & \multirow{2}{*}{0.000} \\
\hline & $\mathrm{B}$ & $11.46 \pm 4.03$ & $12.11 \pm 4.07$ & \\
\hline \multirow{2}{*}{$\begin{array}{l}\text { Change in MAP (Tb) - } \\
\text { (T1.5) }\end{array}$} & A & $2.96 \pm 1.60$ & $3.10 \pm 1.75$ & \multirow{2}{*}{0.000} \\
\hline & B & $5.60 \pm 3.16$ & $5.92 \pm 3.30$ & \\
\hline \multirow{2}{*}{ Change in MAP (Tb) - (Ti) } & A & $17.06 \pm 3.58$ & $17.92 \pm 3.76$ & \multirow{2}{*}{0.000} \\
\hline & $\mathrm{B}$ & $22.42 \pm 4.73$ & $23.77 \pm 4.87$ & \\
\hline \multirow{2}{*}{ Change in MAP (Tb) - (T0i) } & A & $1.96 \pm 4.89$ & $1.96 \pm 5.23$ & \multirow{2}{*}{0.000} \\
\hline & $\mathrm{B}$ & $11.08 \pm 7.14$ & $11.67 \pm 7.49$ & \\
\hline \multirow{2}{*}{ Change in MAP (Tb) - (T1i) } & A & $0.38 \pm 5.20$ & $2.90 \pm 5.58$ & \multirow{2}{*}{0.000} \\
\hline & $\mathrm{B}$ & $9.62 \pm 8.08$ & $10.13 \pm 8.50$ & \\
\hline \multirow{2}{*}{ Change in MAP (Tb) - (T2i) } & A & $7.92 \pm 5.07$ & $8.23 \pm 5.34$ & \multirow{2}{*}{0.000} \\
\hline & $\mathrm{B}$ & $14.46 \pm 7.78$ & $15.28 \pm 8.12$ & \\
\hline \multirow{2}{*}{ Change in MAP (Tb) - (T3i) } & A & $14.68 \pm 4.94$ & $15.37 \pm 5.12$ & \multirow{2}{*}{0.000} \\
\hline & $\mathrm{B}$ & $19.44 \pm 7.58$ & $20.56 \pm 7.86$ & \\
\hline \multirow{2}{*}{ Change in MAP (Tb) - (T5i) } & A & $13.62 \pm 4.99$ & $14.25 \pm 5.19$ & \multirow{2}{*}{0.000} \\
\hline & $\mathrm{B}$ & $18.34 \pm 7.41$ & $19.40 \pm 7.70$ & \\
\hline \multirow{2}{*}{ Change in MAP (Tb) - (T8i) } & A & $11.82 \pm 5.29$ & $12.34 \pm 5.54$ & \multirow{2}{*}{0.000} \\
\hline & B & $16.38 \pm 7.30$ & $17.31 \pm 7.60$ & \\
\hline \multirow{2}{*}{$\begin{array}{l}\text { Change in MAP }(\mathrm{Tb}) \text { - } \\
\text { (T10i) }\end{array}$} & A & $10.34 \pm 5.01$ & $10.79 \pm 5.23$ & \multirow{2}{*}{0.001} \\
\hline & B & $14.48 \pm 7.40$ & $15.30 \pm 7.74$ & \\
\hline
\end{tabular}

$\mathrm{p}$ value $<0.001$ is highly significant

Table 4: Comparison of anxiety score (AS) and sedation score at various time intervals between two groups.

\begin{tabular}{|lllll|}
\hline \multirow{2}{*}{$\begin{array}{l}\text { Time } \\
\text { intervals }\end{array}$} & & Group A & Group B & P value \\
\hline \multirow{2}{*}{ Base line } & Anxiety & 1.32 & 1.26 & 0.677 \\
\cline { 2 - 5 } & $\begin{array}{l}\text { Sedation } \\
\text { score }\end{array}$ & 1.00 & 1.00 & --- \\
\hline \multirow{2}{*}{$\mathbf{1}$ hour } & Anxiety & 1.00 & 1.12 & 0.310 \\
\cline { 2 - 5 } & $\begin{array}{l}\text { Sedation } \\
\text { score }\end{array}$ & 1.14 & 1.06 & 0.186 \\
\hline \multirow{2}{*}{$\mathbf{1 . 5}$ hour } & $\begin{array}{l}\text { Anxiety } \\
\text { Sedation }\end{array}$ & 0.68 & 0.88 & 0.038 \\
\cline { 2 - 5 } & score & 1.36 & 1.10 & 0.002 \\
\cline { 2 - 5 } & $\begin{array}{l}\text { Anxiety } \\
\text { Sedation }\end{array}$ & 0.56 & 0.76 & 0.035 \\
\hline score & 1.44 & 1.14 & 0.001 \\
\hline
\end{tabular}

Comparison of mean MAP is shown in table 3. In both pregabalin and clonidine groups, the MAP remained below the baseline value $(\mathrm{Tb})$ at all the time intervals from T0.5 to T10i, so no pressor response was observed in the form of increase in mean SBP or MAP from the baseline value $(\mathrm{Tb})$.

Maximum rise in MAP was seen at 1 minute after intubation (T1i) but it was still below baseline $(\mathrm{Tb})$ in both groups. Comparison of anxiety and sedation score (AS) at various time intervals between two groups is shown in table 4.Both clonidine $(200 \mu \mathrm{g})$ and pregabalin $(150 \mathrm{mg})$ provided adequate anxiolysis and sedation in preoperative period. The difference in mean sedation and anxiety score was statistically significant $(\mathrm{p}<0.05)$ at $1 \mathrm{hr}$ and $1.5 \mathrm{hr}$ after giving premedication between clonidine group and pregabalin group with pregabalin providing more pronounced sedation and anxiolysis than clonidine. 


\section{DISCUSSION}

Laryngoscopy is one of the core anaesthesia skills that every anaesthesiologist needs to master. Although under general anaesthesia, the patients are well anaesthesized before performing laryngoscopy and tracheal intubation, reflex cardiovascular response to this noxious stimulus still arises as described by Reid and Brace. ${ }^{3}$ Anxiety, an unpleasant emotion, is another factor that can adversely influence the anaesthetic induction and patient recovery.

Present study was done to evaluateand compare the efficacy of oral pregabalin $150 \mathrm{mg}$ and clonidine $200 \mu \mathrm{g}$ for attenuation of pressor response to intubation. The sedation, anxiety and side effects were also assessed. Both groups were comparable with regard to age, gender, BMI or ASA physical status $(p>0.05)$. Duration of laryngoscopy and intubation in the two groups was comparable with mean being $11.94 \pm 1.50 \mathrm{sec}$ in group A and $11.98 \pm 1.35 \mathrm{sec}$ in group $\mathrm{B}(\mathrm{p}>0.05)$ (Table 1$)$. It is observed that pressor response to intubation increases with increase in duration of laryngoscopy and intubation. In the present study the mean duration of laryngoscopy and intubation was kept at minimum possible time and did not exceed 15 seconds. All intubations were performed by a senior experienced anaesthesiologist present in operation theatre. It was observed that there was no statistically significant difference regarding distribution of mallampatti score of patients in both groups $(p>0.05)$.It is well known that increase in HR, SBP and MAP is more pronounced in patients with higher mallampatti score possibly due to longer intubation time. Therefore, only MPG I and MPG II patients were taken for purposes of this study. Present study has shown that both clonidine and pregabalin attenuated the hemodynamic response to laryngoscopy and intubation with respect to HR. In clonidine group, the mean HR remained below the baseline value $(\mathrm{Tb})$ at all the time intervals so no pressor response was observed in the form of increase in mean HR from the baseline value (Tb) (Table 2). In pregabalin group, the mean HR remained below the baseline value $(\mathrm{Tb})$ at most of the the time intervals but increased above baseline $(\mathrm{Tb})$ just after intubation (TOi) and 1 minute after intubation (T1i). This increase in HR was lower than expected increase in HR to the tune of $26-66 \%$ if no specific measures are taken as stated in the similar study conducted by Gupta et al. ${ }^{15}$ Maximum rise in mean HR from the baseline was by $2.02 \%$ at 1 minute after intubation (T1i) (Table 2).

Present study has shown that both clonidine and pregabalin attenuated the hemodynamic response to laryngoscopy and intubation with respect to MAP (Table 3). However, MAP was better controlled in clonidine group as compared to the pregabalin group (Table 3 ). In pregabalin group, maximum fall in mean MAP from the baseline was by $17.92 \%$ after induction (Ti), which was within the permissible limit of $25 \%$. In clonidine group, maximum fall in mean MAP from the baseline was by $23.77 \%$ after induction (Ti), which was within the permissible limit of $25 \%$ (Table 3). Our findings are similar to study done by Gupta et al. where they compared the efficacy of oral premedication with pregabalin $150 \mathrm{mg}$ versus clonidine $200 \mu \mathrm{g}$ for haemodynamic stability during laryngoscopy and pneumoperitoneum in laparoscopic cholecystectomy. They concluded that both drugs have effective role in blunting hemodynamic response in comparison to control group and was statistically significant before induction and $1 \mathrm{~min}$ after intubation ( $\mathrm{p}$ value $<0.05)$ at $5 \mathrm{~min}$ and 10 min after intubation. ${ }^{15}$

Raichurkar A et al. did a comparison with oral pregabalin and clonidine for blunting the intubation response with $150 \mathrm{mg}$ and $200 \mu \mathrm{g}$ respectively in two groups of 30 patients each. They observed that the mean HR following laryngoscopy and intubation among the groups receiving clonidine was lesser than among the group receiving pregabalin and was statistically significant at 1 minute and 3 minutes after intubation. ${ }^{16}$ Similarly, Thomas et al did a study to compare the effect of oral pregabalin $(150 \mathrm{mg})$ and clonidine $(200 \mu \mathrm{g})$ on cardiovascular response from laryngoscopy and endotracheal intubation. They observed that at all observation periods, the HR of clonidine group was found to be lower than that of pregabalin group. ${ }^{17}$ Our findings are also in accordance with study conducted by Soni et al who did a comparative clinical evaluation of oral clonidine vs. pregabalin premedication for attenuation of haemodynamic response to laryngoscopy and intubation. They observed that clonidine $(200 \mu \mathrm{g})$ is better in decreasing the HR as compared to pregabalin $(150 \mathrm{mg})$ which was statistically significant after induction and $10 \mathrm{~min}$ post laryngoscopy and intubation. ${ }^{18}$ Both clonidine $(200 \mu \mathrm{g})$ and pregabalin $(150 \mathrm{mg})$ provided adequate anxiolysis and sedation in preoperative period which is in accordance with studies conducted by Gupta et al, Chandra et al and Waikar et al. ${ }^{13,15,19}$

\section{Limitations}

This study was a small attempt to compare the efficacy of oral clonidine and pregabalin to attenuate pressor response to laryngoscopy and intubation with few inherit limitatios. As patients with MPG I and II were enrolled in the study, the results may not be generalized to the patients with difficult airway (MPG III and IV). As only normotensive patients upto 60 years were enrolled in the study, the results may not be generalized to elderly and hypertensive patients. Use of blood pressure monitoring and measurement of biochemical markers of stress like plasma catecholamines or cortisol would have added to the significance of the study. Larger multicenteric studies should be carried out in future to substantiate the current findings.

\section{CONCLUSION}

Both clonidine $(200 \mu \mathrm{g})$ and pregabalin $(150 \mathrm{mg})$ are effective oral premedicant drugs for attenuation of the 
pressor response to laryngoscopy and endotracheal intubation. However, clonidine provided better control of hemodynamics after intubation. Pregabalin produced more pronounced sedation and anxiolysis.

\section{Funding: No funding sources}

Conflict of interest: None declared

Ethical approval: The study was approved by the Institutional Ethics Committee

\section{REFERENCES}

1. King BD, Harris LC. Reflex circulatory responses to direct laryngoscopy and tracheal intubation performed during general anaesthesia. Anesthesiol. 1951;12950:556-66.

2. Kovac AL. Controlling the hemodynamic response to laryngoscopy and endotracheal intubation. J Clin Anesth. 1996;8:63-79.

3. Reid LC, Brace DE. Irritation of the respiratory tract and its reflex effect upon the heart. Surg GynecObst. 1940;70:157.

4. Burstein CL, Lopinto FJ, Newman W. Electrocardiographic studies during endotracheal intubation: effects during usual routine techniques. Anesthesiol. 1950;11:224-37.

5. AbouMadi MN, Keszler H, Yocoub JM. Cardiovascular reactions to laryngoscopy and tracheal intubation following small and large intravenous dose of lidocaine. Cand Anaesth Soc J. 1977;24:9-12.

6. Hamill JF, Bedford RF, Weaver DC, Colohan AR. Lidocaine before endotracheal intubation: intravenous or laryngotracheal?. Anesthesiol. 1981;55:578-81.

7. Coleman AJ, Jordan C. Cardiovascular responses to anaesthesia: influence of beta adrenoreceptor blockade with metoprolol. Anaesthesia.1980;35:9728.

8. Fassoulaki A, Kaniaris P. Intranasal administration of nitroglycerine attenuates pressor response to laryngoscopy and intubation of trachea. $\mathrm{Br} \mathrm{J}$ Anaesth. 1983;55:49-52.

9. Davis MJ, Cronin KD, Cowie RW. The prevention of hypertension at intubation: A controlled study of intravenous hydralazine on patients undergoing intracranial surgery. Anaesthesia. 1981;36:147-51.

10. Mikawa K, Obara H, Kusunoki M. Effect of nicardipine on cardiovascular response to tracheal intubation. Br J Anaesth. 1990;64:240-2.

11. Salihoglu Z, Demiroluk S, Demirkiran. Comparison of effects of remifentanil, alfentanil and fentanyl on cardiovascular responses to tracheal intubation in morbidly obese patients. Eur J Anaesthesiol. 2002; $19: 125-8$
12. Sundar AS, Kodali R, Sulaiman S, Ravullapalli H, Karthekeyan R. The effects of preemptive pregabalin on attenuation of stress response to endotracheal intubation and opioid sparinge ffect in patients undergoing off-pump coronary artery bypassgrafting. Ann Car Anaesth. 2012;15:18-25.

13. Waikar C, Singh J, Gupta D, Agrawal A. Comparative study of oral gabapentin, pregabalin, and clonidine as premedication for anxiolysis, sedation, and attenuation of pressor response to endotracheal intubation. Anesth Essays Res. 2017;11:558-60.

14. Singh M, Choudhury A, Kaur M, Liddle D, Verghese M, Balakrishnan I. The comparative evaluation of intravenous with intramuscular clonidine for suppression of haemodynamic changes in laparoscopic cholecystectomy. Saudi J Anaesth. 2013;7:181-6.

15. Gupta K, Sharma D, Gupta PK. Oral premedication with pregabalin or clonidine for hemodynamic stability during laryngoscopy and laparoscopic cholecystectomy: A comparative evaluation. Saudi J Anaesth. 2011;5:179-84.

16. Raichurkar A, Dinesh K, Ravi M, Talikoti AT, Somasekharam P. A comparative study of oral pregabalin and clonidine for attenuation of hemodynamic re-sponses to laryngoscopy and tracheal intubation. J Clin Biomed Sci. 2015;5:25-9.

17. Thomas LS, Vishma K. A comparison of oral pregabalin and oral clonidine for the attenuation of haemodynamic response to laryngoscopy and endotracheal intubation and the time for rescue analgesic in thyroid surgeries. Int $\mathbf{J}$ Sci Res. 2019;8:61-3.

18. Soni M, Grover N, Sood S. A comparative clinical evaluation of oral clonidine vs. pregabalin premedication for attenuation of haemodynamic response to laryngoscopy and intubation- a prospective randomised double blinded placebocontrolled study. J Evid Based Med Health. 2019;6:684-90.

19. Chandra A, Yathish SK, Gupta A, Agarwal DN, Chopra R. Oral premedication with pregabalin or clonidine for attenuating the pressor response to laryngoscopy and tracheal intubation in laparoscopic cholecystectomy. Med J DY Patil Vidyapeeth. 2018;11:532-8.

Cite this article as: Kaur H, Gupta J, Singh A, Singh G, Dahuja A, Rajora P, et al. A comparative study of efficacy of oral pregabalin and clonidine for attenuation of pressor response to intubation. Int $\mathbf{J}$ Basic Clin Pharmacol 2021;10:1095-100. 